\title{
Active damping and robust loop shaping control for harmonic minimization
}

\author{
Oscar Andrew Zongo', John Mbogo Kafuku² \\ ${ }^{1}$ Walailak University International College, Walailak University, Thailand \\ ${ }^{2}$ College of Engineering and Technology, University of Dar-es-salaam, Tanzania
}

\begin{tabular}{l}
\hline Article Info \\
\hline Article history: \\
Received Dec 17, 2020 \\
Revised Feb 26, 2021 \\
Accepted Mar 24, 2021 \\
\hline
\end{tabular}

Keywords:

Harmonic current distortion Power system

Renewable energy technology

Robust loop shaping control

Solar photovoltaic

\begin{abstract}
This paper presents an h-infinity robust loop shaping control and LCL filter to mitigate the effects of harmonic currents in the photovoltaic system integrated with the grid. To eliminate the negative effects of the LCL filter, this work applied notch filter active damping. Existing methods for the elimination of harmonic currents were reviewed. Proportional integral control, fuzzy logic control, h-infinity control, and robust loop shaping control are presented. The grid current was analyzed in the system with all controllers applied to control the voltage source inverter of the system to eliminate harmonics in the grid current caused by the inverter and nonlinear loads for two cases, one being constant loading of the linear and nonlinear load and another is the switching of the nonlinear load during the simulation. The results obtained from the proposed method for the two tests conducted were compared with those from other methods to prove the robustness of the proposed technique. The method manages to reduce the total harmonic distortion of the grid current from $7.85 \%$ to $0.79 \%$ for case 1 and from $11.67 \%$ to $1.14 \%$ for case 2 .
\end{abstract}

This is an open access article under the CC BY-SA license.

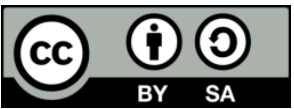

\section{Corresponding Author:}

Oscar Andrew Zongo

Walailak University International College

Walailak University

222 Thaiburi, Thasala, 80161, Nakhon Si Thammarat, Thailand

Email: oscar.zongo1981@gmail.com

\section{INTRODUCTION}

The environmental and climate concerns caused by generators using fossil fuels are some of the reasons for an urgent need of the world to consider introducing alternative energies from solar, wind, geothermal, and others into its existing power production [1]. Solar photovoltaic is one of the widely used renewable energy technologies in the world. But nonlinear loads and converters commonly available in PV systems cause harmonic currents. Harmonics is a critically important concept in electronics. Harmonics affect the quality of $\mathrm{AC}$ electricity delivered to homes and facilities and the performance of equipment that uses this electricity. Harmonics can increase energy costs and reduce the lifespan of the hardware. In some cases, harmonics can overheat electrical conductors, creating a fire risk. Additionally, the control of the voltage source inverter (VSI) is highly affected by the presence of harmonic currents which contribute to the poor power quality in the system. The current distortion level is commonly indicated by the total harmonic distortion (THD) given by [2]:

$$
T H D_{i}=\sqrt{\sum_{n=2}^{\infty} \frac{I_{n}^{2}}{I_{1}}}
$$


Where:

$I_{1}=$ fundamental current.

$I_{n}=$ current at $\mathrm{n}^{\text {th }}$ harmonic

Several techniques have been applied to damp harmonic currents in a grid-connected PV system. The methods use filters to connect the VSI with the grid and controllers to control the VSI. The filters applied are such as L, LC, LCL filters which interface the VSI with the grid. The conventional proportional-integral controller, fuzzy logic control, optimal control, and robust control have been widely used to control the VSI. Most of the optimal and robust control methods have been designed based on the dynamic model of the LCL filter. Additionally, low pass and notch filters have been part of these control strategies. However, there is a lack of h-infinity methods for harmonic current distortion. Thus, this research aims at bridging this gap in the existing literature.

From the literature review of the existing techniques, some presented below, this paper presents a new current compensation control method that focuses on the reduction of the grid current THD. The contribution of this research work which has not been done before is an improvement in the THD of the PV system by applying robust loop shaping control for the voltage source inverter (VSI), filtering actions of an LCL filter, and active damping using notch filters. The results obtained after simulations show the robustness of the proposed method in damping out harmonic currents.

L. El Iysaouy, et al., in [3] compare the performance of CL and LCL filters in THD with both filters manage to reduce the THD to less than 5\% fulfilling the requirements of the IEEE 1574-2014. Authors in [4] added more functions to the proportional resonance (PR) current controller to minimize THD of the 3rd harmonic from $0.45 \%$ to $0.1 \%$, the 5th harmonic from $0.6 \%$ to $0.25 \%$, and the 7 th harmonic from $0.43 \%$ to $0.4 \%$. In [5] a control strategy based on parallel-connected LCL-type inverters is used for harmonic voltage distortion. Passive damping is added to the LCL filter in [6] for improving the power quality in a solar photovoltaic system. Not only the grid voltage THD is reduced from $0.59 \%$ to $0.08 \%$ but also the grid current THD has dropped from $10.71 \%$ to $1.17 \%$ and the inverter current THD is reduced from 10.70 to $4.9 \%$. Electromagnetic interference (EMI) filter and LCL filter are combined to form a hybrid technique named EMI-LCL filter for harmonic and EMI noise suppression for single-phase SiC-MOSFET grid-connected inverter [7].

W. A. A. Saleh, et al., in [8] apply the nearest level control (NLC) method to a 13-level transistorclamped H-bridge (TCHB) inverter to reduce the harmonic content because this control structure consists of two TCHB cells supplied with two asymmetrical DC input sources reduces the number of electronic components in the inverter. The optimal setting of the inverter's filter elements against irradiance is performed in [2] to eliminate harmonics at low irradiance levels. The test is conducted under faulty conditions.

M. A. Razak, et al., in [9] manage to minimize 5th, 7th, 11th, and 13th harmonics caused by semiconductor devices and converters in a PV system by using a passive filter. A Hammerstein adaptive filter is proposed in [10]. The method is capable of extracting the positive sequence components of the grid voltage during imbalance. This parameter is used to estimate the unit templates and the proposed control strategy is left for load current fundamental components extraction. The control strategy limits the THD to the IEEE-519 standards.

\section{PV SYSTEM WITH AN L FILTER}

The grid-connected PV system which includes the PV source, the DC/DC converter, the VSI, and an L filter is shown in Figure 1 [10].

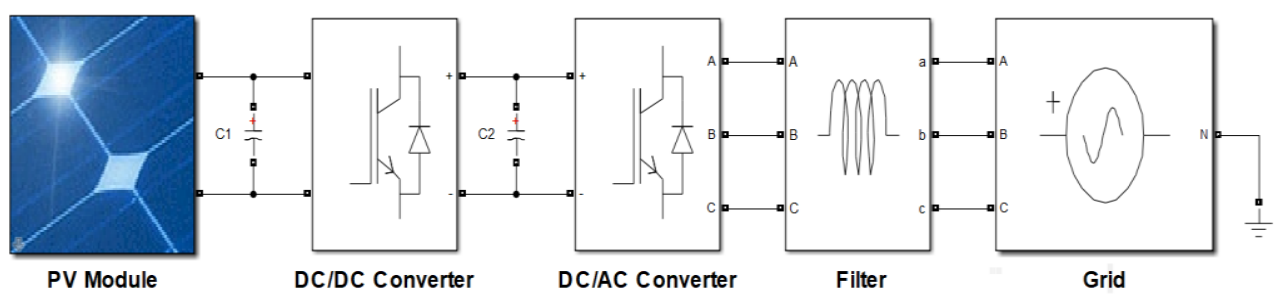

Figure 1. A grid-connected PV system with an L filter 


\subsection{PI control}

The reference gate signal voltages in $d q$ transformation to control the VSI in Figure 1 by using the PI control strategy are given by (2) and (3) and explained in detail in [11]-[13].

$v_{\text {idref }}(t)=v_{g d}-L \omega_{s} i_{q g}+K_{p} e_{d}+K_{i} \int e_{d} d t$

$v_{\text {iqref }}(t)=v_{g q}+L \omega_{s} i_{d g}+K_{p} e_{q}+K_{i} \int e_{q} d t$

Where $e_{d}=i_{\text {dref }}-i_{g d}$ and $e_{q}=i_{q r e f}-i_{g q}$

\subsection{Fuzzy logic control}

The fuzzification, fuzzy rule base, and defuzzification steps are shown in Figure 2.

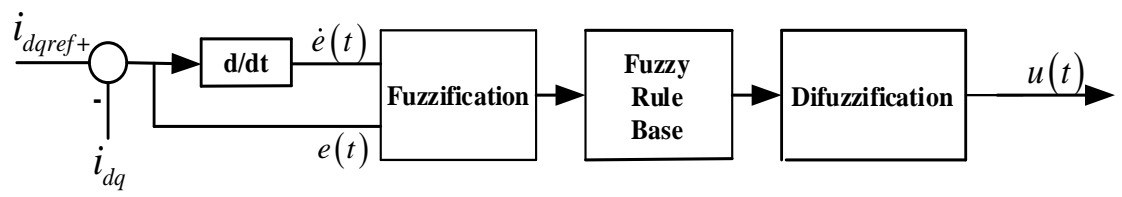

Figure 2. The fuzzy logic control structure

Where:

$e(t)=$ Error

$\dot{e}(t)=$ Derivative of the error

$u(t)=$ Output signal

The design of the "if - and - then"rules is based on qualitative knowledge, deduced from extensive simulation tests using the trial-and-error method.

In this scheme, the PI-controllers used in the previous method in the reference voltage calculation process are replaced by fuzzy logic controllers as shown in Figure 3 [14], [15]. The errors $e(t)$ (obtained from the subtraction of the measured grid currents from their reference currents) and their derivatives $\dot{e}(t)$ are fed to their corresponding fuzzy controllers which output voltage signals summed up with the measured grid voltages and cross-coupling components to obtain $d q$-axis reference voltages. Then, these $d q$-axis voltages are converted into the $a b c$ reference frame.

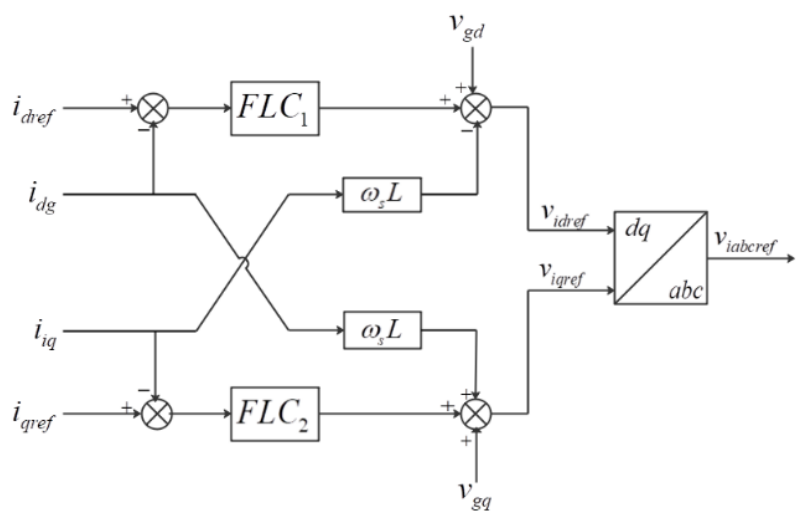

Figure 3. FLC of current loops 
The fuzzy rules are as shown in Table 1 and defined as follows: negative big for NB, negative medium for NM, negative small for NS, negative very small for NVS, zero for ZE, positive very small for PVS, positive small for PS, positive medium for PM, and positive big for PB.

Table 1. Fuzzy logic rules

\begin{tabular}{llllllll}
\hline \multicolumn{8}{c}{$e(t)$} \\
$\dot{e}(t)$ & $N B$ & $N M$ & $N S$ & ZE & $N S$ & $N M$ & $N B$ \\
\hline$N B$ & NM & NM & NM & NS & NS & NS & ZE \\
$N M$ & NM & NM & NS & ZE & NS & ZE & PM \\
$N S$ & NB & NM & NS & NS & ZE & PB & PS \\
$Z E$ & NM & NS & NM & ZE & PB & PS & PM \\
$P S$ & NB & NB & ZE & PS & PS & PM & PB \\
$P M$ & NM & ZE & PM & PM & PS & PM & PB \\
$P B$ & ZE & PB & PB & PM & PM & PB & PB \\
\hline
\end{tabular}

\section{PV SYSTEM WITH AN LCL FILTER}

In this configuration, instead of an L filter used in Figure 1, an LCL filter interfaces the PV system with the grid as shown in Figure 4 [16], [17].

The filter in Figure 4 is represented by its equivalent circuit in Figure 5 [18] and its transfer function block diagram in Figure $6, V_{i}$ which denotes the inverter voltage, $V_{g}$ denotes the grid voltage, $\omega_{s}$ is the grid voltage angular frequency, $C$ and $v_{c}$ is the filter capacitance and capacitor voltage respectively, $i_{i}$ is the inverter current, $i_{g}$ is the grid current, $R_{i}, R_{g}, L_{i} . L_{g}$ is the filter resistances and inductances, respectively. The current is flowing from the inverter to the grid.

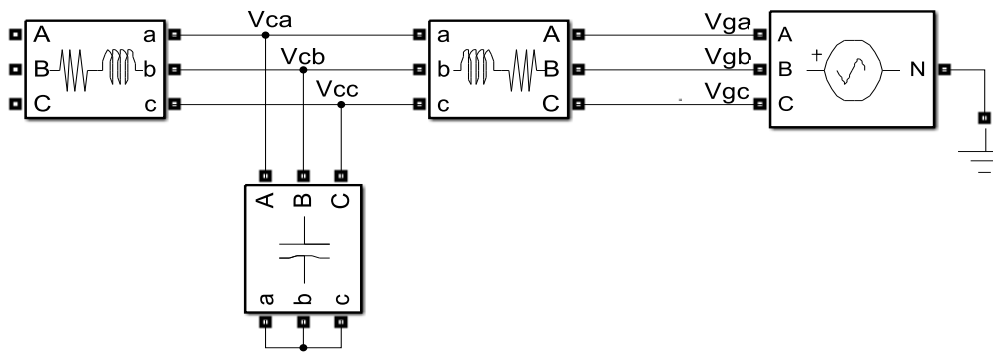

Figure 4. An LCL filter is connected to the grid

The Bode plot of the filter in Figure 7 shows that the filter generates a large overshoot at the resonance frequency. This overshoot results in the amplification of the harmonic amplitude at the resonance frequency, thus increasing the content of higher-order harmonics in the grid current. Therefore, damping resistance connected in series with the capacitor can be used to decrease the overshoot and resonance in the filter while maintaining the merits of the filter [16], [19]. This method is called passive damping.

But, the presence of the damping resistance contributes to the increase in losses because the current $I_{C}$ flows through it as explained in [20]. The losses increase as $R_{d}$ increase. Additionally, the performance at steady-state and during transients is poor. To overcome this drawback active damping based on notch-filter is introduced and is used in this work instead of the damping resistance.

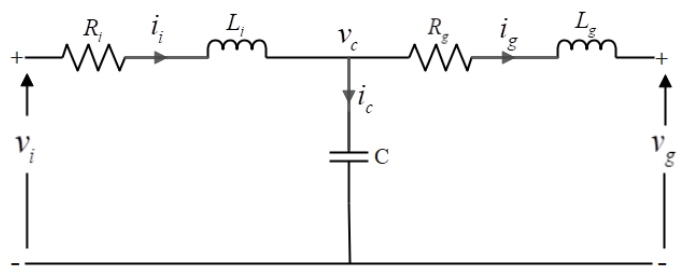

Figure 5. LCL filter equivalent circuit

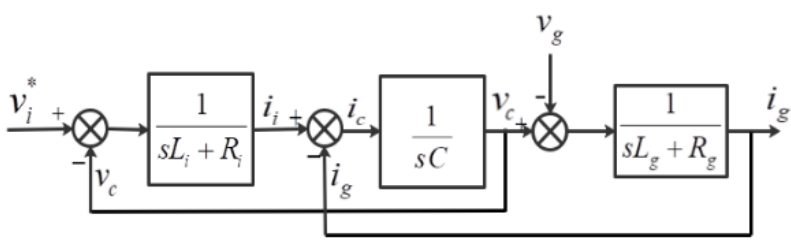

Figure 6. LCL filter plant model 
Signals in a narrow band around a given frequency are attenuated by a notch filter [17]. It can be tuned to reject frequencies near an LCL filter's resonance frequency, removing the resonant peak. Generally, the notch filter's transfer function is given by,

$$
G_{N}(s)=\frac{s^{2}+2 \xi_{1} \omega_{n} s+\omega_{n}^{2}}{s^{2}+2 \xi_{2} \omega_{n} s+\omega_{n}^{2}}
$$

Where:

$\omega_{n}=$ Natural frequency

$\xi_{1}, \xi_{2}=$ Damping factors

The Bode plot of the LCL filter with and without damping is shown in Figure 8 [21] with the notch filter transfer function being.

$$
G_{N}(s)=\frac{s^{2}+25.94 s+5.286 \times 10^{\wedge} 8}{s^{2}+2530 s+5.286 \times 10^{\wedge} 8}
$$

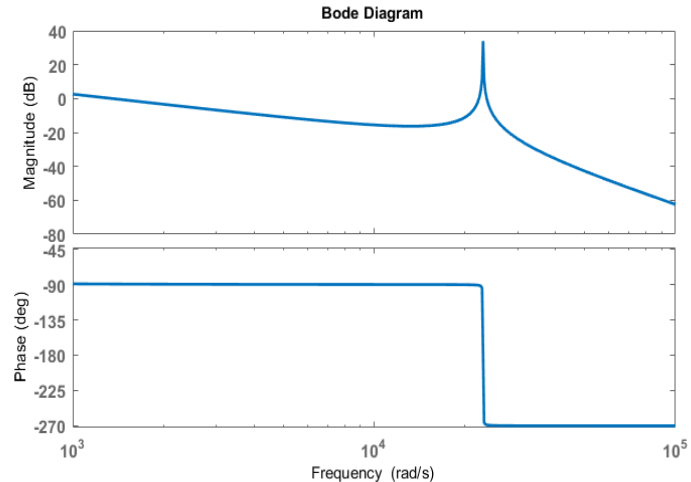

Figure 7. Bode plot of an LCL filter

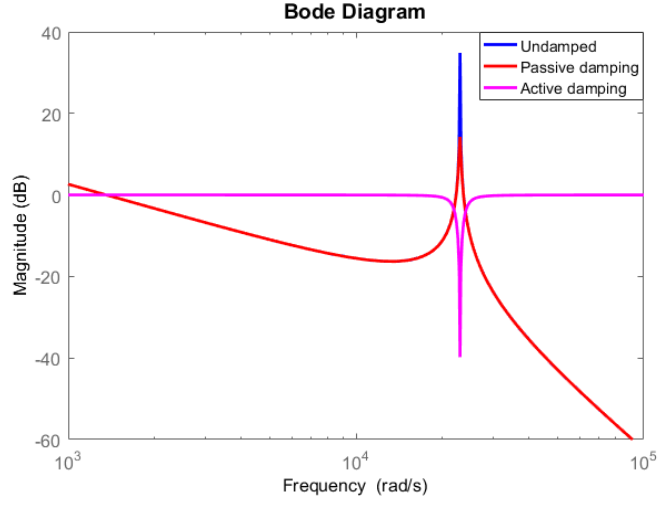

Figure 8. Bode plot of the undamped and damped LCL filter

\subsection{H-infinity control}

The block diagram representation of h-infinity optimization is shown in Figure 9 [22].

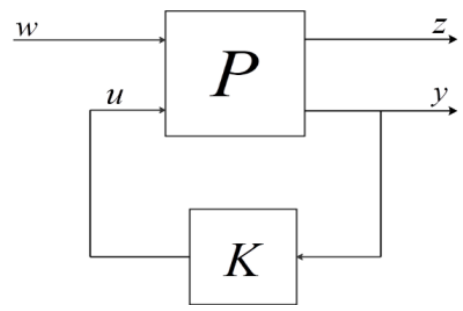

Figure 9. The standard $\mathrm{H} \infty$ configuration

Where:

$$
\begin{aligned}
& w=\text { Disturbance input } \\
& u=\text { Control input } \\
& z=\text { Error output to be minimized } \\
& y=\text { Output of the plant }
\end{aligned}
$$

The method seeks for the controller $K$ to minimize the error $z$. 
$\left\|T_{w \rightarrow Z}(P, K)\right\|_{\infty}$

Subject to $K$ stabilizes $P$.

The objective function is the Hळ-norm of the closed-loop performance $T_{w \rightarrow z}(P, K)$. This reduces the $\mathrm{H} \infty$-norm of the transfer function from $w$ to $z$ less than a pre-determined positive number $\gamma$ to achieve system stability. The Hळ-norm can be mathematically expressed as;

$$
\left\|T_{w z}(s)\right\|_{\infty}<\gamma
$$

\subsubsection{H-infinity controller implementation}

An LCL filter plant model shown in Figure 6 is used to synthesis the controller $K$. The synthesis is carried out by the command "hinfsyn" available in the robust control toolbox of MATLAB and implemented in SIMULINK as shown in Figure 10 [23].

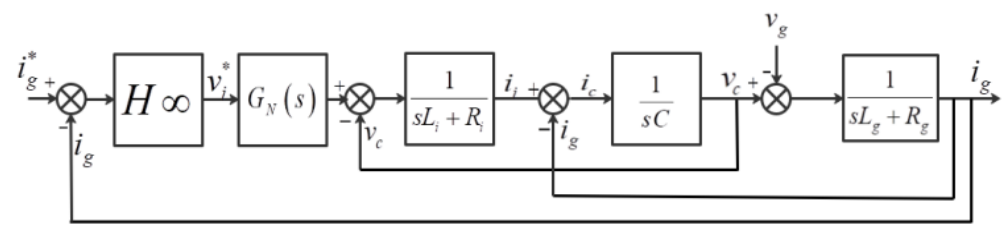

Figure 10. LCL filter plant model with the Hळo current controller and notch filter

\subsection{Robust h-infinity loop shaping control}

The configuration of the loop shaping control with the plant $P$, controller $K$, input $r$, output $y$, and disturbance $d$ and noise $n$ is shown in Figure 11 [24].

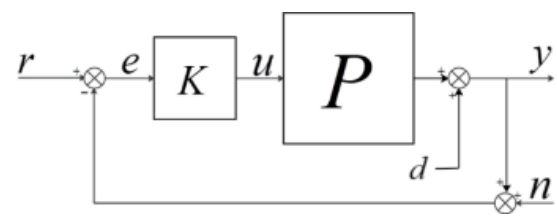

Figure 11. Loop shaping control block diagram

The open-loop transfer function of the system is given by:

$$
L=P K
$$

The output $y$ can be written as,

$$
y=P_{d} d+P K(r-y-n)
$$

The error is,

$$
e=r-y-n
$$

Multiplying both sides of (9) by identity matrix and solve for the output $y$ gives,

$$
y=(I+P K)^{-1} P K r+(I+P K)^{-1} P_{d} d-(I+P K)^{-1} P K n
$$

The sensitivity of the system can be given by,

$$
S=(I+P K)^{-1}
$$


Complementary sensitivity can be given by,

$$
T=(I+P K)^{-1} P K
$$

Substituting (8) into (12) and (13), Sensitivity and Complementary sensitivity can be written as,

$$
\begin{aligned}
& S=(I+L)^{-1} \\
& T=(I+L)^{-1} L
\end{aligned}
$$

Let the addition of sensitivity and complementary sensitivity equal to the identity,

$$
S+T=I
$$

Therefore, the error can be written as,

$$
e=S r-S P_{d} d+T n
$$

The frequency response of the loop shaping controller is shown in Figure 12 [24] and must satisfy the following conditions: i) strong amplification in the low-frequency region, and ii) weak amplification in the high-frequency region.

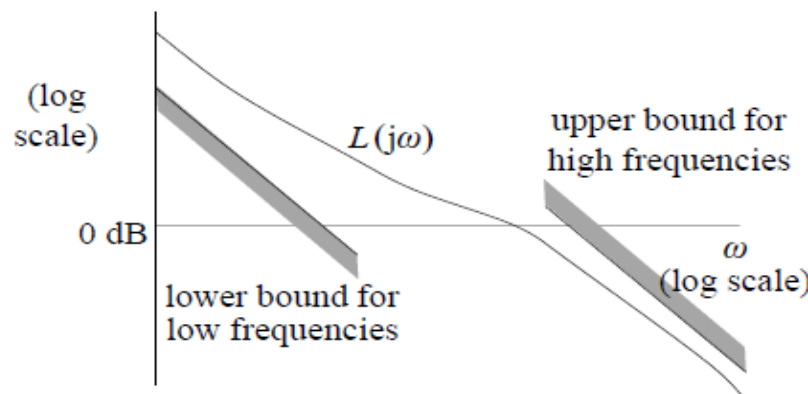

Figure 12. Robust bound of the loop shape

The above frequency response ensures: i) stability improvementii, ii) uncertainty compensation, iii) disturbance rejection, and iv) noise attenuation.

The requirement for $y$ tracking $r$ is

$$
y=r\left\{\begin{array}{l}
\frac{L}{L+1}=1 \\
\frac{1}{1+L}=0
\end{array}\|L\|>>1\right.
$$

\subsubsection{Loop shaping controller synthesis}

An LCL filter plant model shown in Figure 6 is used to synthesis the controller. The synthesis is carried out by the command"loopsyn" available in the robust control toolbox of MATLAB and implemented in SIMULINK as shown in Figure 13 [23].

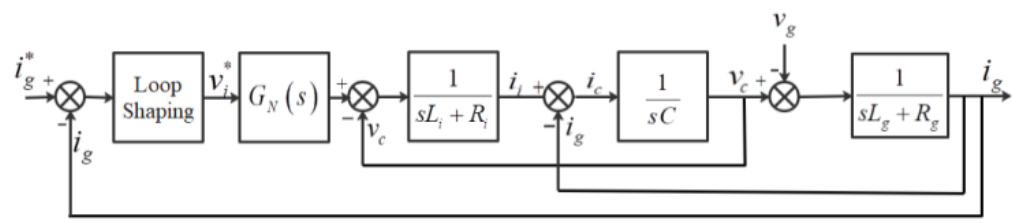

Figure 13. LCL filter plant model with the loop shaping current controller, and notch filter. 
The steps in the design of the controller are:

1) Specify target loop-shape transfer function whose performance and robustness bounds are as in Figure 12.

2) Use the target loop-shape to shape the nominal plant (Figure 6) to make its singular values match that of the target loop shape.

3) Compute the loop-shaping controller ' $K$ ' and the number ' $\gamma$ ' that makes the singular value plot of the shaped loop matches the target loop shape where ' $\gamma$ ' is in the range of $1<\gamma<3$ and indicates the accuracy to which the optimal loop shape matches the desired loop shape.

The chosen desired loop shape was $G_{d}(s)=\frac{8}{s}$ and the obtained number $\gamma=1.4163$ which is within the specified range. The singular value plot of the plant with the controller is shown in Figure 14. The plot shows that the shaped plant optimally tracks the desired loop shape. Moreover, it can be seen from the upper half of the plot that the singular value plot of the open-loop gain best fits with the reciprocal of the singular value plot of the sensitivity (S) function, and in the lower half (below $0 \mathrm{~dB}$ line) the singular value plot of the complementary sensitivity $(\mathrm{T})$ function matches that of the open-loop gain. All these ensure good performance, reference tracking, and disturbance rejection.

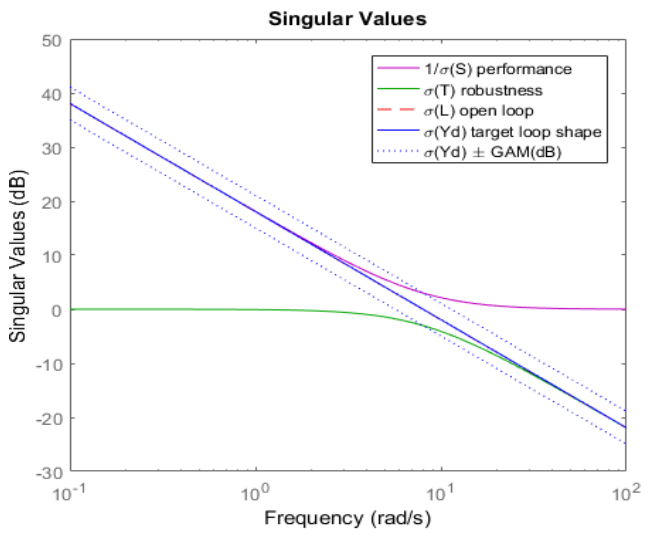

Figure 14. Singular values plot of the plant with the controller.

\section{RESULTS AND DISCUSSION}

The validity of the system is checked with the controllers implemented in MATLAB/SIMULINK for computer simulation to simulate the final system for different circumstances to analyze the system behavior. The use of a sim power system, Mamdani fuzzy inference system, and robust control toolbox provided the flexibility in designing the high rating system for actual implementation. The simulations were run on a PC having Intel Core i5, a $3.20 \mathrm{GHz}$ processor with $8 \mathrm{~GB}$ RAM. The sample time is taken $20 \mu \mathrm{s}$. The effectiveness of the controllers is checked by considering two cases. In each case, an analysis is carried out and results are recorded for stability analysis. The PV system parameters are shown in Table 2.

Case 1: The system is simulated for $2 \mathrm{~s}$ under full load conditions which includes linear and nonlinear loads.

Case 2: This case examines how the switching effects contribute to the increase in harmonics in the system and the response of the control schemes against switching transients. The system is simulated initially with linear load and then nonlinear load switched on and removed later.

Table 2. Parameters of the PV system

\begin{tabular}{lc}
\hline \multicolumn{1}{c}{ Parameter } & Value \\
\hline Grid voltage $V_{L-L}$ & $380 \mathrm{~V}$ \\
DC bus voltage $v_{d c}$ & $650 \mathrm{~V}$ \\
Grid frequency $f$ & $50 \mathrm{~Hz}$ \\
Inverter-side resistance $R_{i}$ & $0.01 \Omega$ \\
Inverter-side inductance $L_{i}$ & $0.7 \mathrm{mH}$ \\
Grid-side resistance $R_{g}$ & $0.001 \Omega$ \\
Grid-side inductance $L_{g}$ & $0.04 \mathrm{mH}$ \\
Filter capacitance $C$ & $50 \mu F$ \\
Damping resistance $R_{d}$ & $0.0001 \Omega \Omega$ \\
\hline
\end{tabular}




\subsection{Results-constant linear and nonlinear load}

The system is simulated for $2 \mathrm{~s}$ for constant linear and nonlinear load. Simulations were recorded between $\mathrm{T}=1.9 \mathrm{~s}$ to $\mathrm{T}=2 \mathrm{~s}$ for all control schemes. During PI control the THD of the grid current was $7.85 \%$ as shown by the FFT analysis plot in Figure 15 and its corresponding grid current waveform in Figure 16. After the application of the fuzzy logic control, the distortion of the grid current dropped to $2.72 \%$ as shown in Figure 17 and its grid current in Figure 18 showing significant improvement. H infinity control managed to further reduce the THD to $1.52 \%$ as shown in Figure 19. At this point, the grid current ripples remain a few (see Figure 20). The application of the robust h-infinity loop shaping control removed all the distortions of the grid current leaving the waveform almost smooth as can be seen in Figure 22 with a reduction in THD dropping to 0.79 (Figure 21). The simulation waveforms show that the system with robust h infinity loop shaping controller's performance is better in terms of dynamics and grid current smoothing. Moreover, the loop shaping-based controller is faster and reduces ripples in grid current and hence lesser deviation from the reference value.

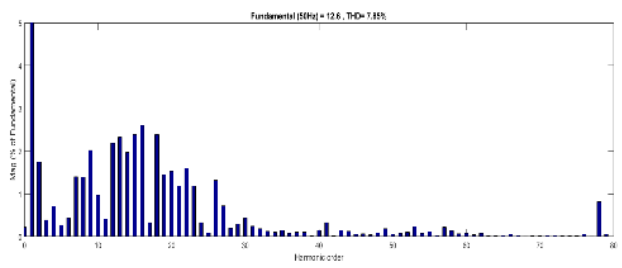

Figure 15. Harmonic spectrum-PI control

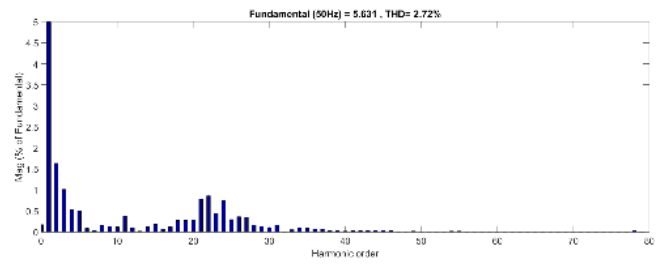

Figure 17. Harmonic spectrum-FLC

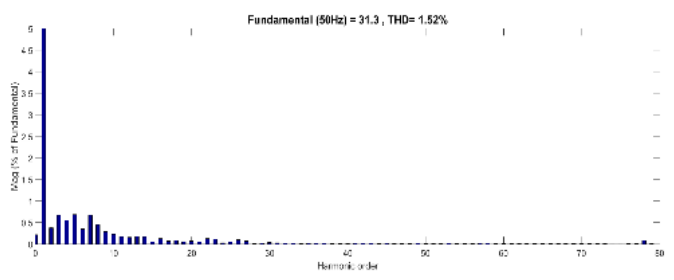

Figure 19. Harmonic spectrum-H infinity

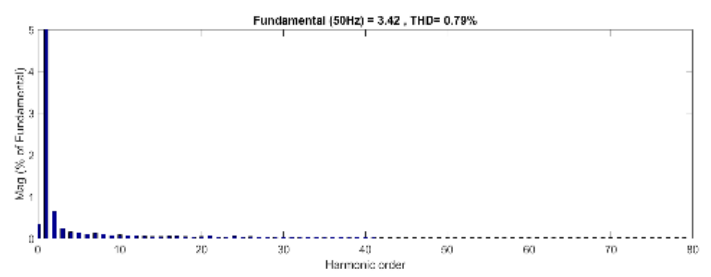

Figure 21. Harmonic spectrum-Loop shaping

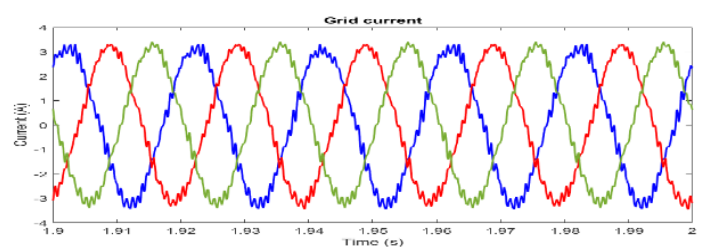

Figure 16. Grid current with the PI controller

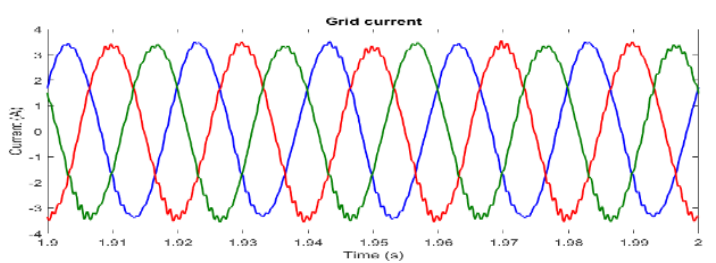

Figure 18. Grid current with an FLC

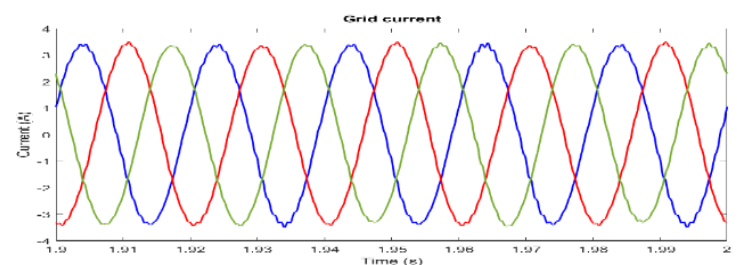

Figure 20. Grid current with H-infinity control

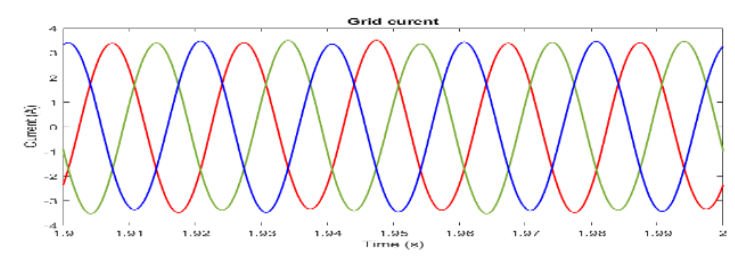

Figure 22. Grid current with robust Loop shaping control 


\subsection{Results-constant linear load and switching of nonlinear load}

The system is simulated from $0.95 \mathrm{~s}$ to $1.1 \mathrm{~s}$ for constant linear load and switching of nonlinear load between $1.00 \mathrm{~s}$ and $1.05 \mathrm{~s}$. The simulation results for all controllers are shown in Figures 23 to 30 . The nonlinear load is switched on at $1.00 \mathrm{~s}$ and switched off at $1.05 \mathrm{~s}$ for obtaining the switching transient response of the system. The simulation waveforms show that the system with a robust loop shaping controller's performance is the best in terms of dynamics and grid current smoothing. Figures 23, 25, 27, and 29, show the performance of the simulated harmonics of the system during the switching of the nonlinear load. These harmonic spectrums show that the harmonics increase due to the switching transients of the nonlinear load. In this case, the transients have increased the harmonic contents of the grid current approximately 1.45 times the values recorded in the first case. With PI control the THD is $11.67 \%$ from $7.85 \%$ recorded in the first test (see Figure 23). This is verified by the system response when using the PI controller. The scheme is the poorest as the switching of the nonlinear load at 1.00 s caused the shooting of the current to about $5.2 \mathrm{~A}$ for the blue phase and about $-5 \mathrm{~A}$ for the red phase (see Figure 24).

This was followed by approximately near steady-state values but with big ripples in the current waveform for all three phases. When the load was removed from the system at $1.05 \mathrm{~s}$, no switching transients occurred. The waveforms became smooth but slightly unstable. Fuzzy logic control managed to reach the allowable distortion margin set by IEEE-519 standards (THD of not more than 5\%) because with this scheme the THD is $3.98 \%$ from $2.72 \%$ of the previous test (see Figure 25). The grid current waveform's red phase is $-4.5 \mathrm{~A}$ and blue phase shot to $4.5 \mathrm{~A}$ from its reference value due to the switching of the nonlinear load and slight variations of the green phases can be seen in Figure 26 followed by dropping of the current to the steady-state value with some ripples lower than those of the PI control. When the load was switched off at $1.05 \mathrm{~s}$ the grid current gained stability and the waveforms became smooth again for all three phases. Hinfinity controller and robust loop shaping give $2.22 \%$ and $1.14 \%$ of THD respectively despite the switching effect of the nonlinear load (see Figures 27 and 29) although higher than the values obtained in the first case which were $1.52 \%$ for h-infinity control and $0.79 \%$ for the loop shaping control. The grid currents shown in Figures 28 and 30 prove the results of the harmonic spectrums in Figures 27 and 29. The grid current when the system is controlled by h-infinity control managed to reduce the effect of the switching transients to the higher amount. The red phase of the current waveform varied to only $-4 \mathrm{~A}$ and the blue phase to $4 \mathrm{~A}$ after the switching of the nonlinear load. After that, all three phases settled to their steady-state values with some slight variations and very few ripples. When the load was removed from the supply there were very small ripples before disappearing and then all the three phases were smooth and stable to the higher amount. Moreover, the Loop shaping controller's response to switching transients was superior as the waveforms of the grid current show very slight distortions at the instant of nonlinear load switching, during nonlinear loading, and after it was removed. The method has proved to be the fastest in damping switching effects of the nonlinear load (see Figure 30).

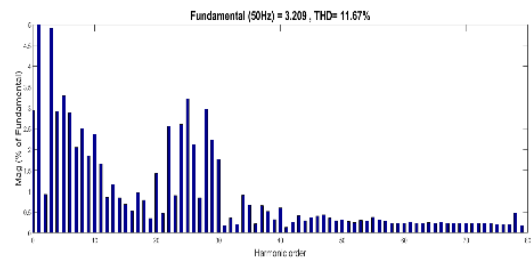

Figure 23. Harmonic spectrum PI control

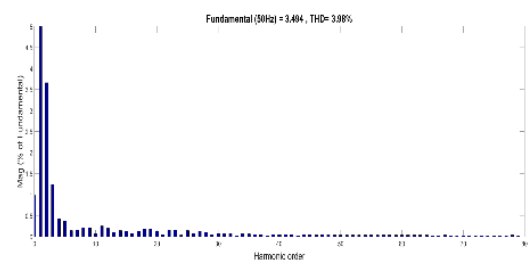

Figure 25. Harmonic spectrum-FLC

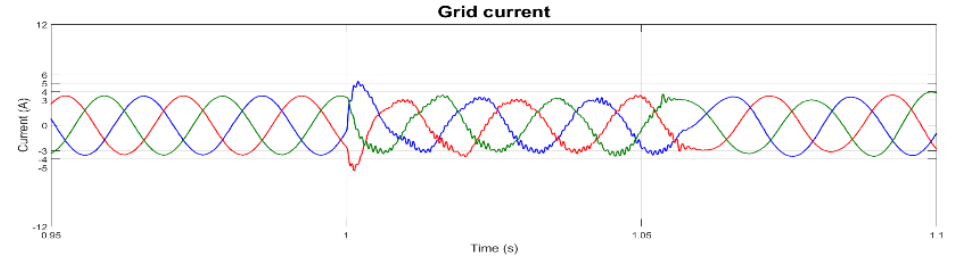

Figure 24. Grid current with the PI controller

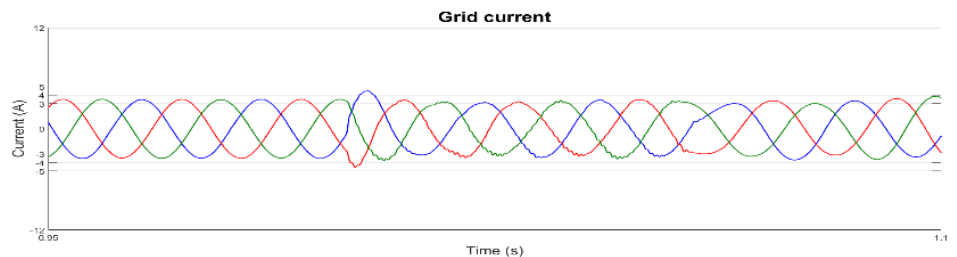

Figure 26. Grid current with an FLC 


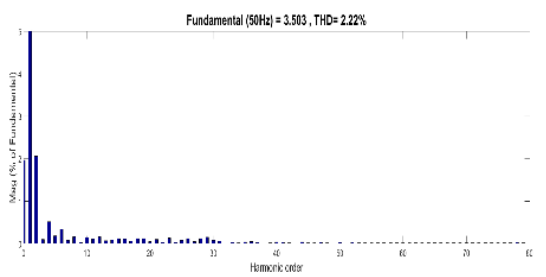

Figure 27. Harmonic spectrum-Hinfinity

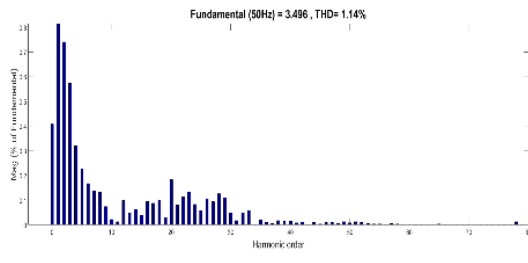

Figure 29. Harmonic spectrum-loop shaping

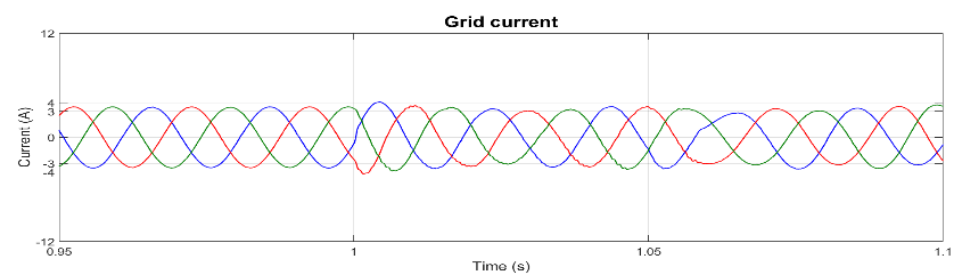

Figure 28. Grid current with H-infinity control

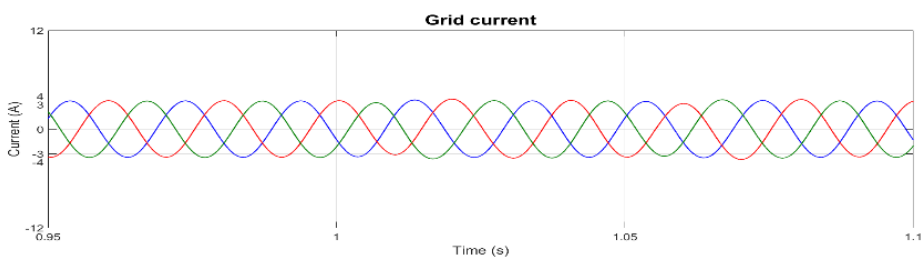

Figure 30. Grid current with robust loop shaping control

\subsection{Discussion}

With the PI controller, the grid current has serious damaging oscillations. The application of the FLC has significantly reduced the THD. Additionally, LCL filter, notch filter, and h-infinity control have proved to be a better control strategy over PI control and the FLC. Results obtained from simulations show the robustness of the robust loop shaping control strategy compared to all the other controllers.

This experiment has applied the L filter and LCL filter and notch filter and the one in [3] employed LC and LCL filters for THD. Both studies have ended up with the reduction of the harmonic currents, the LCL filter being the best. The application of a notch filter shows positive effects in [20] as in this research although the control strategies are different. Both schemes have managed to significantly reduce the THD of the grid current below $5 \%$ as required by the IEEE standards. The robustness of LCL in damping harmonics can also be seen in [25] as in this study. The application of h-infinity robust control to damp harmonics is discussed in [26] similar to this study. In [26], a linear matrix inequality LMI technique is part of h-infinity optimization. A robust technique known as linear matrix inequality-linear quadratic regulator (LMI-LQR) is employed in [27] to damp voltage harmonics while this study applies robust loop shaping to reduce current harmonics. This study and the one in [28] both apply LCL filters with different active damping strategies for harmonic reduction. This work uses a notch filter while researchers in [28] prefer washout filter and damping coefficient.

\section{CONCLUSION}

An h-infinity robust loop shaping control for controlling the VSI of a PV system in the presence of the harmonics induced by nonlinear loads and the inverter is presented in this paper. The proposed controller's robustness is demonstrated by the results obtained from experiments with PI, FLC, h-infinity control, and robust h-infinity loop shaping control. In the paper, the harmonics in the grid current triggered by non-linear loads and the VSI are removed by the LCL and notch filters, as well as the control scheme based on robust h-infinity loop shaping. The suitability of the proposed approach has been demonstrated by simulation exercises for the two cases. The grid current THD for the two experiments with the proposed controller is the lowest, and the grid current waveforms in both cases are the smoothest and most stable for the majority of the simulation period as opposed to the other methods. These results prove the robust loop shaping method's effectiveness in controlling the VSI.

\section{ACKNOWLEDGEMENTS}

This work is sponsored by Walailak University International College, Walailak University, Nakhon si Thammarat, Thailand. 


\section{REFERENCES}

[1] L. Farah, A. Haddouche, and A. Haddouche, "Comparison between proposed fuzzy logic and ANFIS for MPPT control for photovoltaic system," International Journal of Power Electronics and Drive System (IJPEDS), vol. 11, No. 2, pp. 1065-1073, 2020, DOI: 10.11591/ijpeds.v11.i2.pp1065-1073.

[2] L. Xiong, M. Nour, and M. Shahin, "Harmonic analysis of the high penetration level of photovoltaic generation in a distribution network and solution studies," 8th International Conference on Modeling Simulation and Applied Optimization (ICMSAO), 2019, pp. 1-5, DOI: 10.1109/ICMSAO.2019.8880387.

[3] L. El Iysaouy, A. Baškys, and M. Lahbabi, "Impact of CL and LCL low pass output filters on high order harmonics of single-stage photovoltaic microinverter," Proceedings of The International Symposium on Advanced Electrical and Communication Technologies (ISAECT), 2019, pp. 1-5, DOI: 10.1109/ISAECT.2018.8618819.

[4] A. Mohamed, S. Saimin. "THD performance of single-phase five-level inverter using proportional resonant and harmonic compensators current controller," International Journal of Power Electronics and Drive System (IJPEDS), vol. 11, pp. 1423-1429, 2020, DOI: 10.11591/ijpeds.v11.i3.pp1423-1429.

[5] L. Zhou, et al., "Harmonic voltage distortion damping method for parallel-connected LCL-Type inverters in islanded operation," IEEE Transactions on Industrial Electronics, vol. 66, pp. 9032-9044, 2019, DOI: 10.1109/TIE.2018.2878124.

[6] R. David, A. Raj, T. Aditya, and M. R. Shinde, "Power quality enhancement of grid-connected solar photovoltaic system using LCL filter," Proceedings of The International Conference on Power Electronics \& IoT Applications in Renewable Energy and its Control (PARC), 2020, pp. 334-339, DOI: 10.1109/PARC49193.2020.236621.

[7] S. Jiang, Y. Liu, Z. Mei, J. Peng, and C-M. Lai, "A magnetic integrated LCL-EMI filter for a single-phase SiCMOSFET grid-connected inverter," IEEE Journal of Emerging and Selected Topics in Power Electronics, vol. 8, pp. 601-617, 2020, DOI: 10.1109/JESTPE.2019.2937816.

[8] W. A. A. Saleh, N. A. M. Said, W. A. Halim, "Harmonic minimization of a single-phase asymmetrical TCHB multilevel inverter based on nearest level control method," International Journal of Power Electronics and Drive System (IJPEDS), vol. 11, pp. 1406-1414, 2020, DOI: 10.11591/ijpeds.v11.i3.pp1406-1414.

[9] M. A. Razak, N. Islam, and A. U. Zaman, "Design and simulation of PV based harmonic compensator for threephase load," International Conference on Computer, Communication, Chemical, Materials, and Electronic Engineering (IC4ME2), 2019, pp. 1-6, DOI: 10.1109/IC4ME247184.2019.9036568.

[10] V. Jain, and B. Singh, "Hammerstein adaptive filter based control technique for optimum operation of a grid interfaced PV system," IEEE International Conference on Environment and Electrical Engineering and IEEE Industrial and Commercial Power Systems Europe (EEEIC/ I\&CPS Europe), 2019, pp. 1-6, DOI: 10.1109/EEEIC.2019.8783615.

[11] B. Fekkak, M. Menaa, and B. Boussahoua, "Control of transformerless grid-connected PV system using average models of power electronics converters with MATLAB/Simulink," Solar Energy, vol. 173, pp. 804-813, 2018, DOI: $10.1016 /$ j.solener.2018.08.012.

[12] R. K. Sharma, S. Mudaliyar, and S. Mishra, "Power management and economic load dispatch based control of hybrid PV-Battery-Diesel standalone AC system," IEEMA Engineer Infinite Conference (eTechNxT), 2018, pp. 1-6, DOI: 10.1109/ETECHNXT.2018.8385352.

[13] J. C. Colque, E. Ruppert, and J. L. Azcue, "Performance analysis of a three-phase photovoltaic generation system with active filtering functions connected to the electrical grid," Proceedings of 13th IEEE International Conference on Industry Applications (INDUSCON), 2018, pp. 249-255, DOI: 10.1109/INDUSCON.2018.8627249.

[14] B. Rached, M. Elharoussi, and E. Abdelmounim, "Fuzzy logic control for wind energy conversion system based on DFIG," International Conference on Wireless Technologies, Embedded and Intelligent Systems (WITS), 2019, pp. 1-6, DOI: 10.1109/WITS.2019.8723722.

[15] A. Ouaia, L. Mokrania, M. Machmoumb, and A. Houarib, "Control and energy management of a large scale gridconnected PV system for power quality improvement," Solar Energy, vol. 171, pp. 893-906, 2018, DOI: 10.1016/j.solener.2018.06.106.

[16] S. S. Das, and A. Panda, "LCL filter based solar photovoltaic distributed generation system," IEEE International Conference on Power Electronics, Drives, and Energy Systems (PEDES), 2018, pp. 1-6, DOI: 10.1109/PEDES.2018.8707818.

[17] F. Mulolani, A. Althobaiti, and Y. Alamoudi, "Notch-Filter active damping of LCL filter resonance in a gridconnected inverter with variable grid inductance," 2019 Advances in Science and Engineering Technology International Conferences (ASET), 2019, pp. 1-6, DOI: 10.1109/ICASET.2019.8714393.

[18] S. Hafsi, M. Dhaoui, A. S. S. Lassaad, "Fuzzy logic control of grid-connected PWM rectifiers with LCL filters," International Conference on Green Energy Conversion Systems (GECS), 2017, pp. 1-6, DOI: 10.1109/GECS.2017.8066268.

[19] M. C Band, D. K. Sameeksha, and M. Miranda, "Analysis of LCL filter design for a grid-tied power converter and its effect on THD," 2020 7th International Conference on Signal Processing and Integrated Networks (SPIN), 2020, pp. 850-855, DOI: 10.1109/SPIN48934.2020.9070927.

[20] M. Popescu, A. Bitoleanu, and V. Suru, "On the design of LCL filter with passive damping in three-phase shunt active power filters," 2016 International Symposium on Power Electronics, Electrical Drives, Automation, and Motion (SPEEDAM), 2016, pp. 825-830, DOI: 10.1109/SPEEDAM.2016.7525899.

[21] H. Ge, Y. Zhen, Y. Wang, and D. Wang, "Research on LCL filter active damping strategy in the active power filter system," The 9th International Conference on Modelling, Identification, and Control (ICMIC), 2017, pp. 476-481, DOI: 10.1109/ICMIC.2017.8321691. 
[22] A. A. Z. Diab, A-H. M. El-Sayed, H. H. Abbas, and M. A. El Sattar, "Robust speed controller design using h_infinity theory for high-performance sensorless induction motor drives," Energies Journal, vol. 12, no. 5, p. 961, 2019, DOI: 10.3390/en12050961.

[23] C. Tarasantisuk, and N. Phankong, "Active damping of PR based current control in LCL filter for the gridconnected inverter," 2019 The 16th International Conference on Electrical Engineering/Electronics, Computer, Telecommunications, and Information Technology 9ECTI-CON, 2019, pp. 573-576, DOI: 10.1109/ECTICON47248.2019.8955432.

[24] M. Zebbar, Y. Messlema, A. Gouichichea, and M. Tadjineb, "Super-twisting sliding mode control and robust loop shaping design of RO desalination process powered by PV generator," Desalination, vol. 458, pp. 122-135, 2019, DOI: 10.1016/j.desal.2019.02.011.

[25] M. Chapparband, D. K. Sameeksha, M. Miranda, "Analysis of LCL filter design for a grid-tied power converter and its effect on THD," 2020 7th International Conference on Signal Processing and Integrated Networks (SPIN), 2020, pp. 850-855, DOI: 10.1109/SPIN48934.2020.9070927.

[26] H. Qian, Q. Xu, J. Zhao, and X. Yuan, "A robust GPS-based control scheme for power-sharing and quality improvement in a microgrid," Electrical Power and Energy Systems, vol. 123, p. 106324, 2020, DOI: 10.1016/j.ijepes.2020.106324.

[27] R. Bimarta, and K-H Kim, "A robust frequency-adaptive current control of a grid-connected inverter based on LMI-LQR under polytopic uncertainties," IEEE Power \& Energy Society, vol. 8, pp. 28756-28773, 2020, DOI: 10.1109/ACCESS.2020.2972028.

[28] A. Saima, A. Houaria, M. Ait-Ahmed, M. Machmouma, J. M. Guerrero, "Active resonance damping and harmonics compensation in distributed generation based islanded microgrids," Electric Power Systems Research, vol. 191, p. 106900, 2021, DOI: 10.1016/j.epsr.2020.106900. 